\title{
Beetle (Coleoptera: Scirtidae) Facilitation of Larval Mosquito Growth in Tree Hole Habitats is Linked to Multitrophic Microbial Interactions
}

\author{
Kirsten Pelz-Stelinski • Michael G. Kaufman • \\ Edward D. Walker
}

Received: 10 September 2010 / Accepted: 3 May 2011 /Published online: 24 May 2011

(C) The Author(s) 2011. This article is published with open access at Springerlink.com

\begin{abstract}
Container-breeding mosquitoes, such as Aedes triseriatus, ingest biofilms and filter water column microorganisms directly to obtain the bulk of their nutrition. Scirtid beetles often co-occur with A. triseriatus and may facilitate the production of mosquito adults under lowresource conditions. Using molecular genetic techniques and quantitative assays, we observed changes in the dynamics and composition of bacterial and fungal communities present on leaf detritus and in the water column when scirtid beetles co-occur with $A$. triseriatus. Data from terminal restriction fragment polymorphism analysis indicated scirtid presence alters the structure of fungal communities in the water column but not leaf-associated fungal communities. Similar changes in leaf and water bacterial communities occurred in response to mosquito presence. In addition, we observed increased processing of leaf detritus, higher leaf-associated enzyme activity, higher bacterial productivity, and higher leaf-associated fungal biomass when scirtid beetles were present. Such shifts suggest beetle feeding facilitates mosquito production
\end{abstract}

\section{K. Pelz-Stelinski $(\square)$}

Entomology and Nematology Department, Citrus Research and Education Center, University of Florida,

700 Experiment Station Road,

Lake Alfred, FL 33850, USA

e-mail: pelzstelinski@ufl.edu

M. G. Kaufman • E. D. Walker

Department of Entomology, Michigan State University,

East Lansing, MI, USA

\section{E. D. Walker}

Department of Microbiology and Molecular Genetics,

Michigan State University,

East Lansing, MI, USA indirectly through the microbial community rather than directly through an increase in available fine particulate organic matter.

\section{Introduction}

Tree holes are small discrete ecosystems that contain heterotrophic communities driven by allochthonous inputs of soluble and particulate organic matter. In Eastern North American tree holes, larvae of the Eastern treehole mosquito, Aedes triseriatus (Say), are usually the dominant macroinvertebrate consumers. Leaves are a typical source of coarse particulate organic matter (CPOM) [48], but animal-derived detritus, such as invertebrate carcasses and fecal material, also supply energy to these systems $[9,50]$. In addition, stemflow runoff brings dissolved organic carbon and nutrients into the habitats $[5,16,19]$. Success of $A$. triseriatus and similar mosquito species is characterized by high adult productivity and body weight at emergence, and is dependent on the nutrition obtained while in the larval stage [45]. The quantity and quality of leaf litter in tree holes are important determinants of successful mosquito production [34, 45], although in general larvae do not directly consume the material. Rather, microorganisms are the main nutritional resource for mosquito larvae, which feed by browsing on container surface microbial biofilms and filtering fine particulate organic matter (FPOM) and microorganisms from the water column [27]. Fungi associated with leaf detritus alone may account for around $10 \%$ of the detrital biomass in tree hole habitats $[19,20]$. Hence, microbial degradation of detritus is a critical link between developing larvae and nutrients as processing by microorganisms incorporates nutrients and otherwise inaccessible carbon from organic detritus. 
Despite previous studies addressing consumption of microorganisms by mosquito larvae in container habitats, microbial food resource dynamics remain ill-defined. Water column-associated bacteria exhibit negligible or inconsistent responses to mosquito presence and, thus far, there have not been any published studies of fungal communities associated with tree hole water columns. Furthermore, larval feeding effects on the composition of water column microbial communities are limited to bacteria and protists $[8,17,19,21,44]$. In contrast, there is convincing support for the importance of microbial communities associated with detritus in previous assessments of tree holes. Increased fungal enzyme activity, and decreased bacterial productivity and abundance are associated with mosquito feeding $[16,17,19,34]$. Despite the response of microorganisms to larvae, the composition of microbial communities in tree holes has been addressed only recently $[18,36$, 37, 49]. In those studies, larval feeding effects were evident on the taxa comprising fungal and bacterial communities associated with leaf detritus, with particular influence on Saccharomycetes, Dothideomycetes, and Chytridiomycota fungal taxa and on Alpha- and Betaproteobacteria.

In the Midwestern and Eastern USA, larval scirtid beetles (Helodes and Prionocyphon spp.) are shredders which often co-occur with $A$. triseriatus in tree holes [2, 32]. Scirtid feeding activity results in the skeletonization of leaf detritus and the associated conversion of CPOM to FPOM, including small leaf particles and feces. Several studies indicate that the presence of these beetles in tree holes conditionally facilitates the survival and development of $A$. triseriatus when leaf litter levels are low by improving the quality of resources available to A. triseriatus [3, 9-11, $31,32]$. Similar processing chain commensalisms benefiting mosquitoes have been reported in pitcher plants. By increasing the conversion of coarse particulate plant material to fine particulates, the midge Metriocnemus knabi facilitates populations of the pitcher plant mosquito Wyeomyia smithii [15]. In addition to mosquito populations, processing chain benefits have been reported to facilitate populations of the ceratopogonid midge Culicoides guttipennis in the presence of Helodid beetles [33]. Increased conversion of leaf material into FPOM is the main mechanism cited for any benefit experienced by mosquitoes in the presence of scirtids $[11,12,30,31]$. Indeed, Daugherty and Juliano [12] demonstrated that additions of scirtid fecal material and its associated microbiota to microcosms increased larval $A$. triseriatus development by providing additional nutrient resources; however, the source of this positive effect (feces, microbiota, or a combination) was not determined. Although the conversion of CPOM into FPOM may benefit foraging larvae by being ingested directly, it may also promote access to fungal material otherwise embedded in the leaf matrix. Furthermore, it is possible that any influence of scirtid feeding on the microbial community may affect mosquitoes given the direct utilization of microorganisms by larvae for nutrient acquisition. By altering the detritus such that the abundance of FPOM is greater, scirtid beetles modify the bottom-up influence of detritus on bacterial and fungal populations. Such blending of "bottom-up" influences and "top-down" trophic cascades are described for aquatic ecosystems, including tree hole container habitats, yet the ramifications of scirtid beetles on microorganisms is poorly understood $[6,7,21,22]$.

Although previous studies have postulated mechanisms for facilitation of mosquito larvae by scirtids, they are limited to measurements of macroscopic changes such as the abundance of FPOM, population densities of mosquitoes, and decomposition of scirtid carcasses [11, 12, 30, 32]. While all of these factors play a role in mosquito growth, these indirect assessments lack the intermediate microbial step linking the trophic levels. Elucidating the effect of scirtid-feeding activity on mosquito productivity requires an assessment of the changes such feeding renders on the microbial community.

In an effort to understand the ecological influences driving mosquito production, we sought to describe microbial mechanisms underlying facilitation of larval $A$. triseriatus growth and development by scirtid beetles via assessments of the microbial community associated with scirtid presence in microcosms simulating natural tree holes. To address the effects of macroinvertebrates on the structure of tree hole microbial communities, we used the culture-independent molecular technique, terminal restriction length polymorphism (T-RFLP) analysis. We postulated that detritus-associated fungal dynamics, rather than water column-associated, would be the most dramatically affected by scirtid presence as this location is the "center of activity" for foraging scirtid larvae [13]. Furthermore, we predicted that mosquito presence should have a dissimilar effect on microbial communities than that of scirtids due to the different feeding modes exhibited by these macroinvertebrates.

\section{Materials and Methods}

\section{Experimental Design}

The microbial dynamics underlying the facilitation of A. triseriatus development by scirtid beetle larvae were investigated by crossing beetle presence/absence with mosquito presence/absence in a multifactorial design with the following scirtid/A. triseriatus ratios: 0:0, 10:0, 10:40, and $0: 40$. The ratios were selected to reflect densities of the macroinvertebrates typically observed in natural tree holes. 
Twelve replicates of each treatment combination were constructed, with one set of six replicates destructively sampled on day 20 , approximately midway through the experiment. Because resource levels mediate the interaction between scirtids and mosquitoes such that facilitation is only apparent when resources are less abundant, low leaf litter rations were used for all replicate microcosms. Individual microcosms simulating natural tree holes received 1-g senescent oak leaf pack (Northern Red Oak, Quercus rubra) in $500 \mathrm{ml}$ deionized water. Microcosms (20.3 cm height $\times 7.6 \mathrm{~cm}$ inner diameter) were constructed similar to those described in previous tree hole studies [17, 20, 46]. A 3-ml microbial inoculum, consisting of homogenized tree hole water and particulates, was added to microcosms 3 days prior to the addition of macroinvertebrates. To insure that macroinvertebrates were not present, the microbial inoculum was visually inspected prior to addition.

A. triseriatus, obtained from our colony at Michigan State University, were added as newly hatched first instar larvae. Scirtid beetle larvae, ranging from second to fourth instar, were obtained from local tree holes (Toumey Woodlot, E. Lansing, MI, USA) and replaced semiweekly as necessary to maintain a constant population in scirtid treatments. Replacement beetle larvae were taken from the original stock of scirtids collected for this experiment and rinsed with sterile water before being added to microcosms. Dead beetles were removed to avoid confounding the effect of scirtids by providing additional resources to mosquito or microbial populations. Due to the difficulty of identifying live beetle larvae, scirtids were not identified to species $[10,12,32]$.

\section{Sampling}

Leaf condition was assessed by taking dry weight measurements of leaf disks on days 20 and 40. Leaf disk samples ( $20 \mathrm{~mm}$ diameter) were procured from each microcosm on days 20 and 40 using a cork borer. Leaves were aseptically removed from microcosms and gently placed onto a sterile Petri dish prior to cutting to minimize disruption of the biofilm. Two leaf samples apiece were also collected for assessing bacterial abundance, bacterial productivity, fungal biomass, fungal degradation enzymes, and microbial community structure. Prior to analyses, leaf disk samples were sonicated for $12 \mathrm{~min}$ in an ice bath to obtain the loosely attached, surface-associated microorganisms, as these better represent those encountered by foraging mosquito larvae [18]. In addition to leaf samples, water samples were also taken from microcosms on each sample date. After stirring microcosms to homogenize water and particulates, $15-\mathrm{ml}$ water column samples were removed from microcosms for the analyses indicated above.

Microcosms were checked daily for the presence of adult mosquitoes. Adults were collected and stored at $4^{\circ} \mathrm{C}$ until the microcosm was destructively samples. Larvae were gathered by decanting the remaining microcosm water through a fine mesh sieve and stored at $4^{\circ} \mathrm{C}$. Where possible, we sexed and identified adults, larvae, and pupae to species before lyophilizing the mosquitoes to obtain dry mass measurements.

\section{Bacterial Abundance and Productivity}

Bacterial abundance on the leaf surface and in the water column was quantified from subsamples via direct microscopic counts of bacteria using the 4,6-diamidino-2-phenylindole fluorescent staining procedure $[34,38,46]$. Formalin $(3 \%$ formaldehyde final concentration)-preserved samples were kept under dark conditions at $4^{\circ} \mathrm{C}$ until analysis, then filtered onto black Nucleopore filters $(0.2-\mathrm{mm}$ pore size; Costar, Cambridge, MA, USA). After filtering, samples were stained at a final concentration of $20 \mu \mathrm{g} / \mathrm{ml}$ for $5 \mathrm{~min}$. Two filters and at least 20 fields per filter were counted (a minimum of 200 cells per filter) for each subsample at $1,000 \times$ using a Nikon E800 fluorescent microscope (Nikon, Inc. Melville, NY, USA).

Bacterial productivity was estimated by measuring the incorporation of $\left[{ }^{3} \mathrm{H}\right]$-leucine $(50 \mathrm{Ci} / \mathrm{mmol}$, Life Science, Boston, MA, USA) into bacterial biomass using the microcentrifuge tube method [21, 42]. Labeled leucine was added at a final concentration of $25 \mathrm{nM}$. It was determined previously that saturation of uptake kinetics occurs at 100 and $400 \mathrm{nM}$ for water and leaf samples, respectively $[17,19,20]$. Samples were incubated for $30 \mathrm{~min}$ at $20^{\circ} \mathrm{C}$ to allow for the incorporation of labeled leucine into bacterial biomass. Following incubation, 5\% trichloroacetic acid was added to terminate the reaction and precipitate protein. Samples were subsequently rinsed and concentrated as described in prior microcosm studies [17, 20]. Standard liquid scintillation counting of samples was conducted in a Beckman LS6500 scintillation counter (Beckman Coulter, Inc., Fullerton, CA, USA).

\section{Fungal Biomass}

Fungal biomass was estimated using ergosterol, a sterol associated with fungal cell walls, as a surrogate measurement $[28,43]$. Leaf disk subsamples were placed in high performance liquid chromatography (HPLC) grade methanol and stored in the dark at $4{ }^{\circ} \mathrm{C}$ prior to extraction and quantification of ergosterol using HPLC and UV detection $[16,19]$.

\section{Enzyme Activity}

Fungal activity was estimated by measuring the degradation of xylose and cellobiose as surrogate measures of fungal enzymes. Leaf enzyme activity was assayed through incubations of leaf 
disk subsamples with two methylumbelliferyl (MUF)-labeled substrates, 4-methylumbelliferyl- $\beta$-D-cellobioside and 4methylumbelliferyl- $\beta$-D-xyloside, which estimate cellobiohydrase and xylosidase activities, respectively. These substrates are analogous to plant polymers and thus provide an estimate of leaf-associated carbohydrase activity [19]. MUF was liberated upon enzymatic cleavage of the substrates during 1.5 -h incubation at $22^{\circ} \mathrm{C}$. Unbound MUF, which fluoresces at $360 \mathrm{~nm}$, was measured using a 96-well Hoefer DyNA Quest 200 fluorometer (GE Healthcare, Little Chalfont, Buckinghamshire, UK).

\section{Microbial Community Analysis}

The compositions of leaf- and water column-associated microbial communities in microcosms were assessed using T-RFLP analysis, a culture-independent technique that estimates the diversity of microbial "species" present in samples [24, 26]. Six replicate microcosms per treatment were sampled for bacterial and fungal community analysis. Three of the microcosms were destructively sampled on day 20 and three on day 40 . Leaf disk samples were sonicated as described above in sterile phosphate buffered saline to dislodge surfaceassociated microorganisms. Thereafter, DNA was immediately isolated from leaf sonicate and water samples using the MoBio UltraClean soil extraction kit (Carlsbad, CA, USA). Independent amplification of DNA for T-RFLP analysis were performed with two primers sets respectively targeting small subunit (SSU) ribosomal DNA from bacteria (16S rDNA) and fungi (18S rDNA). A 1,300-bp $16 \mathrm{~S}$ rDNA fragment was amplified using universal eubacterial primers $63 \mathrm{~F}$ and 1387R (5'-CAGGCCTAACACATG CAAGTC-3' and 5'-GGGCGGWGTGTACAAGGC-3') [25]. A 762-bp 18S rDNA fragment was amplified using universal fungal primers nu-SSU-0817-59F and nu-SSU-1536-39R (5'-TTAGCATGGA ATAATRRAATAGGA-3' and 5'ATTGCAATGCYCTATCCCCA-3') [4]. Forward primers for each target sequence were fluorescently labeled (6-FAM) at the 5' end (IDT Technologies). Template DNA from fungal and bacterial communities was amplified in three $100-\mu l$ polymerase chain reaction (PCR) reactions per primer set using the Failsafe ${ }^{\mathrm{TM}}$ PCR System (Epicentre Biotechnologies, Madison, WI, USA). Each PCR reaction consisted of $\sim 10$ ng template DNA, $50 \mu$ l Failsafe ${ }^{\mathrm{TM}}$ PCR PreMix buffer E, $1 \mu$ l Failsafe ${ }^{\mathrm{TM}}$ enzyme, and $4 \mu \mathrm{l}$ of each DNA primer. Reactions were held at $94^{\circ} \mathrm{C}$ for $2 \mathrm{~min}$, and then amplified at PCR cycle conditions optimized for each target sequence. For $16 \mathrm{~S}$ rDNA, reaction mixtures were cycled 30 times through the following steps: $45 \mathrm{~s}$ at $94^{\circ} \mathrm{C}$, $30 \mathrm{~s}$ at $68^{\circ} \mathrm{C}$, and $1 \mathrm{~min} 30 \mathrm{~s}$ at $72^{\circ} \mathrm{C}$. For $18 \mathrm{~S}$ rDNA, reaction mixtures were cycled 30 times through the following steps: $45 \mathrm{~s}$ at $94^{\circ} \mathrm{C}, 30 \mathrm{~s}$ at $58^{\circ} \mathrm{C}$, and $1 \mathrm{~min}$ at $72^{\circ} \mathrm{C}$. Both reactions were subjected to a final extension step for $7 \mathrm{~min}$ at $72^{\circ} \mathrm{C}$. PCR products from triplicate reactions were combined to minimize PCR bias and then purified using the Qiaquick $^{\text {TM }}$ PCR purification kit (Qiagen, Valencia, CA, USA). Purified products were digested with the restriction enzymes, MspI and HhaI (New England Biolabs, Cambridge, MA; 200 ng product with one unit of enzyme for $3 \mathrm{~h}$ at $37^{\circ} \mathrm{C}$ ), incubated overnight with $100 \%$ ethanol at $-80^{\circ} \mathrm{C}$, then washed with $70 \%$ ethanol to remove excess salts. Labeled fragments were separated by capillary electrophoresis of digested samples with the PRISM 3100 Genetic Analyzer (Applied Biosystems, Foster City, CA, USA). A one in 50 dilution of digested PCR product was used prevent saturation of the signal detector during electrophoresis. The size and frequencies of each terminal restriction fragment (T-RF) were determined by comparison with a 2500-ROX internal standards (Applied Biosystems) using a peak height detection of 50 fluorescent units (GeneScan software, Applied Biosystems).

\section{Statistical Analysis}

One-way analyses of variance (ANOVA) were used to assess mosquito response variables (survival, emergence time, and total biomass). Multivariate analysis of variance (MANOVA) was used to analyze related bacterial measurements including bacterial abundance and bacterial productivity in the water column and on leaf surfaces (Proc GLM, SAS v. 9.1, SAS Institute, Inc., Cary NC, USA). The activity of fungal degradation enzymes and fungal ergosterol were similarly analyzed in a separate MANOVA. Standardized correlation coefficients (SCCs) were calculated for each MANOVA to determine the magnitude of the contributions made to each variable to the respective measurements included in the analysis [41]. In addition, univariate analysis of variance ("protected" ANOVA) was conducted for dependent variables with significant MANOVA results followed by Bonferroni correction to control the experiment-wide error [39]. Treatment means were separated using Tukey's "honestly significantly different" (HSD) test. Leaf mass lost was analyzed using a standard ANOVA. Means were square root transformed as needed to meet the assumptions of ANOVA.

T-RFLPs were aligned and peak areas determined using the GeneScan software package (Applied Biosystems). A sample was discarded if its combined peak area was less than 1,000 or if a normality plot indicated the presence of significant outliers. In addition, peaks that comprised $<3 \%$ of the community or appeared in fewer than three samples were also discarded. We distinguished "real" peaks by separating signals from baseline noise in electropherograms. T-RFs differing by \pm 1 bp were considered identical. Common peaks were aligned and binned using 
the "T-RFLPs Stats" analysis tools (iBest, http://www. ibest.uidaho.edu/tools/trflpstats/index.php) [1]. The resulting matrices were converted to log ratios of the relative abundance of peak area in each sample, calculated as the peak area of a T-RF divided by total peak area of all fragments in a sample within a 50- to $800-\mathrm{bp}$ range. Profiles from each of the four communities (water column bacteria and fungi and leaf-associated bacteria and fungi) were individually analyzed by principle component analysis (PCA) on the respective covariance matrices to reduce dimensionality. PCA ordinations were conducted using $\mathrm{JMP}^{\circledR}$ Statistical Discovery Software (SAS Institute, Inc., Cary NC, USA). Scores from PCs $1-3$ were subjected to standard ANOVA for treatment comparisons.

\section{Results}

Leaf decomposition decreased significantly in the presence of sciritids $(F=11.96 ; d f=1,23 ; P=0.003)$ such that microcosms containing scirtids had a lower proportion of leaf mass remaining than non-scirtid microcosm (Fig. 1; Tukey's HSD, $\alpha=0.05$ ). Neither mosquito presence solely or with scirtids significantly affected leaf decomposition $(F=0.69 ; d f=1,23 ; P=0.417$; and $F=0.0 ; d f=1,23 ; P=$ 0.962 , respectively). Mosquito survival and total biomass were highest in the presence of scirtid beetles, with correspondingly faster female development time (Table 1), although these differences were not statistically significant.

Scirtids, mosquitoes, and time had significant effects on measurements of bacterial community dynamics

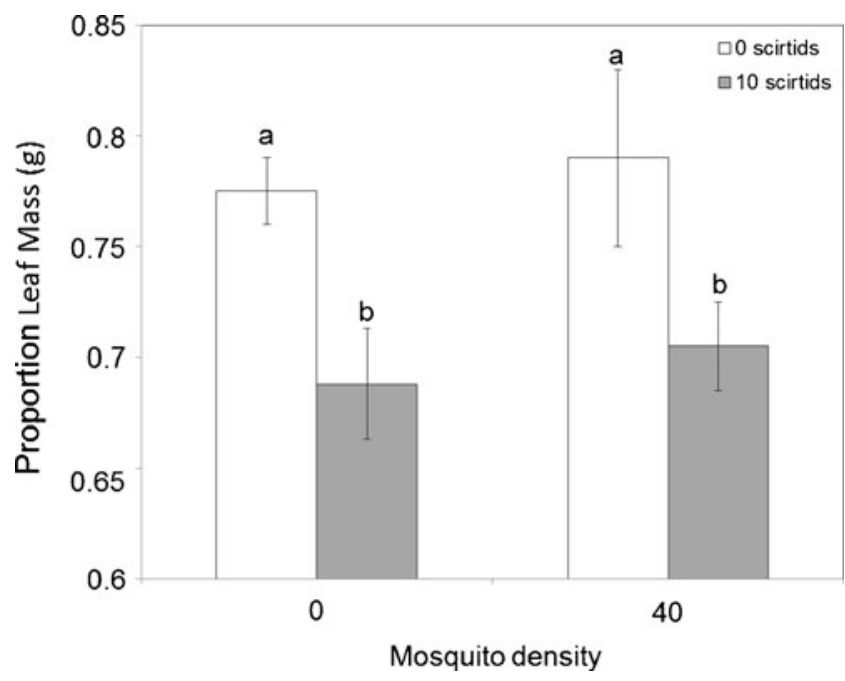

Figure 1 Proportion of leaf mass remaining in microcosms on day 40. White bars no mosquito larvae, gray bars 40 mosquito larvae. Values are means $\pm \operatorname{SE}(N=24)$; lowercase letters significant differences between scirtid densities; means with the same letter not significantly different (Tukey's HSD, $\alpha=0.05$ )
(MANOVA, Table 2). Macroinvertebrate treatment, time, and the interactions among the main effects were primarily explained by changes in the bacterial abundance on leaves (Table 2, SCC). In the water column, bacterial abundance was not significantly affected by the presence of either macroinvertebrate, although a significant decrease in abundance did occur from days 20 to 40 (Fig. 2a). In contrast, leaf surface bacterial abundance was depressed in the presence of macroinvertebrates (Table 3 and Fig. 2b). Under reduced-resource conditions, mosquito larvae significantly lowered bacterial abundance compared with no larvae conditions; however, scirtid presence significantly interacted with mosquito presence on day 20 such that microcosms containing both insects had a greater abundance of leaf-associated bacteria than those containing mosquito larvae alone (Table 3). Although scirtid beetles alone did not significantly decrease bacterial abundance at day 20 ; by day 40 , microcosms containing only scirtids had a lower abundance of bacteria than microcosms with no macroinvertebrates present.

Significant reductions in water column bacterial productivity were evident in the presence of mosquito larvae and productivity remained unchanged whether scirtids were present or absent (Table 3, Fig. 2c). In addition, water column productivity also declined significantly from days 20 to 40 for microcosm treatments. Leaf-associated bacterial productivity was significantly lower in the presence of mosquito and scirtid beetle larvae compared with the no-macroinvertebrate treatment (Table 3, Fig. 2d). Productivity differences were not apparent among microcosms receiving macroinvertebrates, likely in response to the significant interaction between mosquito larvae and scirtid beetles.

The presence of scirtid beetles in microcosms had important effects on the activity and biomass of fungi in microcosms (MANOVA, Table 4). These effects were mainly explained by changes in the concentration of xylosidase and cellobiohydrase (SCC, Table 4). Activity of fungal decomposition enzymes for these substrates was significantly greater $(F=9.28 ; d f=1,36 ; P=0.004$ and $F=8.57 ; d f=1,36 ; P=0.006$, respectively) in leaf samples from microcosms containing scirtids compared with microcosms without scirtid beetles (Fig. 3). In contrast, although fungal biomass (ergosterol concentration) in microcosm leaf samples was numerically greater in microcosms containing scirtids, this effect was not statistically significant. Enzyme activity and biomass, determined by ergosterol measurement, were not significantly influenced by the presence of mosquito larvae in microcosms; however, biomass was significantly influenced by the time main effect (MANOVA, Table 4). Fungal biomass was not significantly influenced by the presence of either A. triseriatus or scirtid larvae; however, the concentration of ergosterol was signif- 
Table 1 Response variable means (SEM) and analysis of variance (ANOVA) results for microcosms containing scirtid beetles and mosquito larvae

\begin{tabular}{|c|c|c|c|c|c|}
\hline & \multicolumn{2}{|c|}{ Scirtid density } & \multicolumn{3}{|c|}{ Effect of scirtids } \\
\hline & 0 & 10 & $F$ & $d f$ & $P$ \\
\hline \multicolumn{6}{|l|}{ Mosquito responses } \\
\hline$\%$ Survival & $40.4(1.6)$ & $51.8(2.3)$ & 2.6 & 1,21 & 0.122 \\
\hline Days to emergence (M) & $24.1(0.6)$ & $25.4(1.4)$ & 0.64 & 1,19 & 0.434 \\
\hline Days to emergence $(F)$ & $32.3(2.7)$ & $27.3(2.8)$ & 1.61 & 1,9 & 0.24 \\
\hline Total biomass (mg) & $2.19(0.31)$ & $3.00(0.35)$ & 2.67 & 1,21 & 0.118 \\
\hline
\end{tabular}

$M$ male, $F$ female

$P=0.019)$. Both time and mosquito presence significantly affected water column bacteria along PC2 $(F=9.3, d f=1,23$, $P<0.001 ; F=31.5, d f=1,23, P<0.001)$. There were no significant effects of treatment on PC3 scores. Both mosquito presence and time significantly affected PC1 scores for leaf surface bacterial communities $(F=45.5$, $d f=1,22, P<0.001 ; F=8.44, d f=1,22, P=0.011)$, while scirtids had only a marginally significant effect $(F=4.6, d f=1$, $22, P=0.048)$. Neither insect presence nor time significantly affected PCs 2 and 3.

T-RFLP analysis yielded 99 T-RFs associated with leaf and 88 T-RFs associated with water column fungal communities. The first three PCs obtained from analysis of T-RF profiles explained 50 and $54.3 \%$ of the total variability in the MspI dataset corresponding to fungal communities in the water column and on leaf surfaces, respectively. Water column fungal communities exhibited significant shifts in response to mosquito presence and time along PC2 $(F=43.6, d f=1,22, P<0.001 ; F=12.4, d f=1,22$, $P=0.003$; Fig. 6). There were no significant effects of any factor on PC1. Mosquito presence, sample date, and the interactions of sample date with mosquito presence and with scirtid presence significantly affected water-associated fungi along PC3 $(F=3.3, d f=1,22, P=0.011 ; F=23.6, d f=1$, along PC1 $(F=16.9, d f=1,23, P=0.001 ; F=16.9, d f=1,23$,

Table 2 Multivariate analysis of variance (MANOVA) for the effect scirtid beetles, mosquito larvae, and sampling time on bacterial community measurements and the standardized canonical coefficients (SCC) of the first canonical variate

\begin{tabular}{|c|c|c|c|c|c|c|c|c|}
\hline \multirow{3}{*}{ Model parameters } & \multicolumn{4}{|l|}{ MANOVA } & \multicolumn{4}{|l|}{$\mathrm{SCC}$} \\
\hline & \multirow[t]{2}{*}{ Pillai's trace } & \multirow[t]{2}{*}{$F$} & \multirow[t]{2}{*}{$d f$} & \multirow[t]{2}{*}{$P$} & \multicolumn{2}{|c|}{ Bacterial abundance } & \multicolumn{2}{|c|}{ Bacterial productivity } \\
\hline & & & & & Water column & Leaf surface & Water column & Leaf surface \\
\hline Scirtid & 0.34 & 3.22 & 4,25 & $0.029^{*}$ & 0.21 & 1.778 & -0.252 & 1.248 \\
\hline Mosquito & 0.597 & 9.25 & 4,25 & $0.000^{*}$ & -0.267 & 0.941 & -0.07 & 0.346 \\
\hline Time & 0.893 & 52.29 & 4,25 & $0.000^{*}$ & -0.481 & 3.176 & 0.358 & -0.324 \\
\hline Scirtid $\times$ mosquito & 0.446 & 5.04 & 4,25 & $0.004^{*}$ & -0.157 & 1.649 & -0.134 & 1.293 \\
\hline Scirtid $\times$ time & 0.596 & 9.25 & 4,25 & 0.170 & -0.109 & 2.889 & 0.639 & -1.047 \\
\hline Mosquito $\times$ time & 0.476 & 5.69 & 4,25 & $0.002^{*}$ & -0.339 & 3.145 & 0.31 & -0.488 \\
\hline Scirtid $\times$ mosquito $\times$ time & 0.327 & 3.04 & 4,25 & $0.036^{*}$ & 0.832 & -2.561 & -0.662 & 0.898 \\
\hline
\end{tabular}

Only the first canonical was significant

$* P<0.05$, significance for MANOVA 

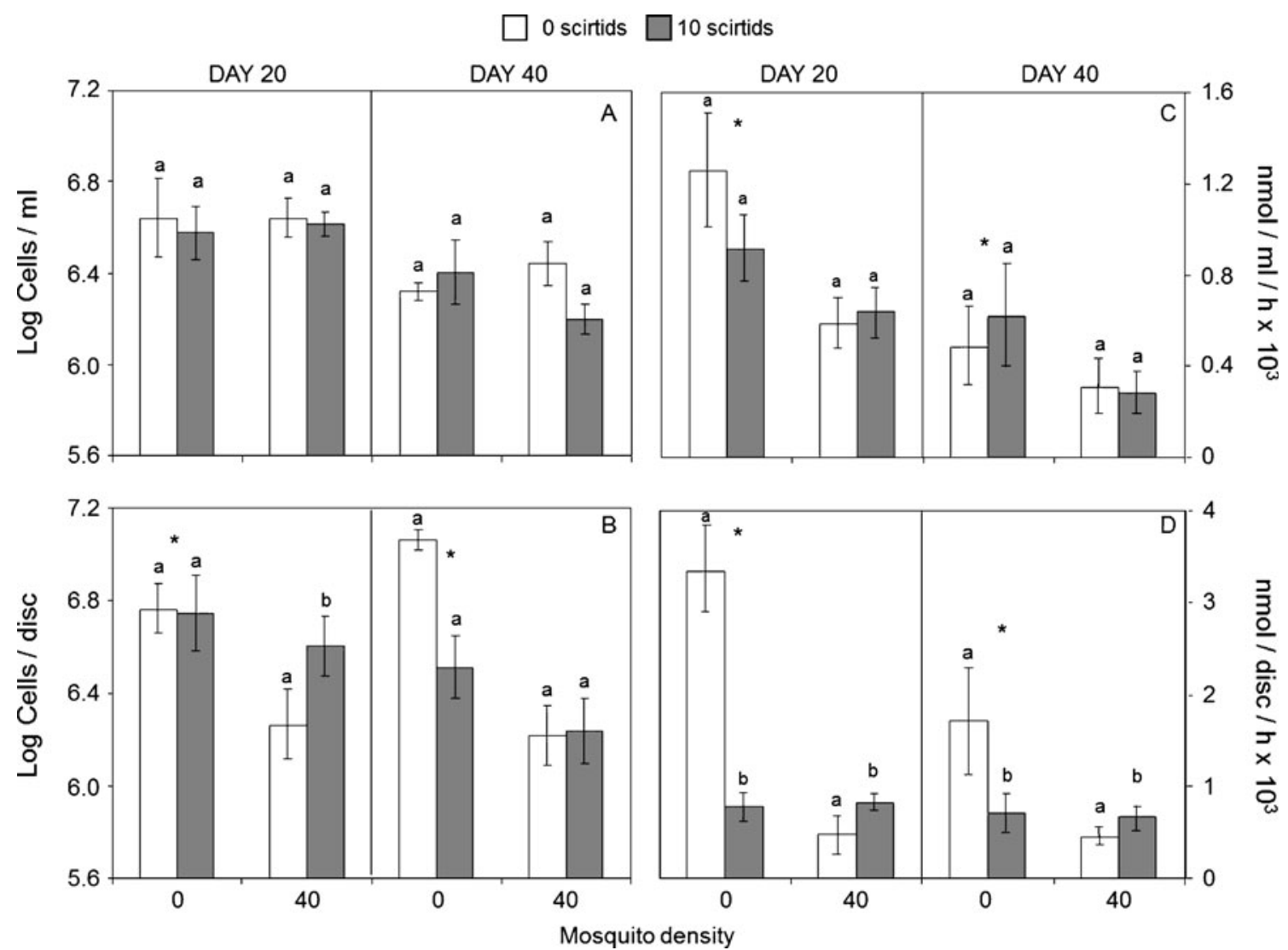

Figure 2 Bacterial abundance (a, b) and production (c, d) in the water column (top panels) and on leaf surfaces (bottom panels). Values are means \pm SE $(N=24)$. Asterisks significant difference

$22, P=0.001 ; F=6.0, d f=1,22, P=0.027 ; F=4.8, d f=1,22$, $P=0.045)$ Similarly, a shift in leaf-associated fungal communities in response to mosquito presence was significant along PC2 $(F=6.19, d f=1,23, P=0.024)$. In general, however, no shifts were evident in leaf fungal communities in response to time or scirtid presence.

HhaI

In comparison to MspI, T-RFLP digestions using HhaI resulted in fewer T-RFs from water column- and leaf-associated bacterial communities (71 and 55, respectively). PC2 scores representing water column bacterial communities were significantly affected by mosquitoes $(F=6.2, d f=1,22, P=0.01)$. Leaf surface bacterial communities represented by principal component axes were significantly affected by scirtids along PC1 $(F=5.1, d f=1,23, P=0.039)$. The percentage of total variation explained by the first three PCs in the HhaI datasets corresponding to water column and leaf surface bacterial communities were $44.7 \%$ and $47 \%$, respectively.

Similar to bacterial communities, fungal communities associated with water and leaf samples produced fewer between mosquito density treatments, bars with lowercase letters significant differences between scirtid densities, means with the same letter not significantly different (Tukey's HSD, $\alpha=0.05$ )

T-RFs (46 and 41, respectively) when digested with HhaI compared with MspI. Water column fungal communities changed in response to the interaction of mosquito presence and time along PC2 $(F=11.5, d f=1,22$, $P=0.004)$. PCs $1-3$ explained $54 \%$ of the total variation associated with T-RFLP profiles in this community. Scirtids did not significantly affect changes in leafassociated fungal communities, although these communities changed in response to the presence of mosquitoes (PC2: $F=45.5, d f=1,23, P<0.001)$ and time (PC1: $F=24.3, d f=1$, 23, $P<0.001$; PC2: $F=8.7, d f=1,23, P=0.010)$. PCA analysis revealed that $56.2 \%$ of the variation in leaf fungal communities was explained by the first three principle components.

\section{Discussion}

This study evaluated the impact of scirtid beetle presence on microbial community dynamics in container habitats. We demonstrated that scirtid beetles increased the decay rate of leaf detritus, accelerated microbial activity on leaf 
Table 3 Summary of ANOVA results for bacterial abundance and bacterial productivity values from microcosm water column and leaf material

\begin{tabular}{|c|c|c|}
\hline Model parameters & $F_{\mathrm{df}}$ & $P$ value \\
\hline \multicolumn{3}{|c|}{ Water column abundance (cells/ml) } \\
\hline Scirtid & $1.22_{1,28}$ & 0.278 \\
\hline Mosquito & $1.37_{1,28}$ & 0.252 \\
\hline Time & $15.26_{1,28}$ & $<0.001^{\mathrm{a}}$ \\
\hline Scirtid $\times$ time & $0.30_{1,28}$ & 0.857 \\
\hline Mosquito $\times$ time & $0.71_{1,28}$ & 0.407 \\
\hline Scirtid $\times$ mosquito & $0.78_{1,28}$ & 0.385 \\
\hline \multicolumn{3}{|c|}{ Leaf surface abundance (cells/disk) } \\
\hline Scirtid & $8.90_{1,28}$ & $0.006^{\mathrm{a}}$ \\
\hline Mosquito & $45.59_{1,28}$ & $<0.001^{\mathrm{a}}$ \\
\hline Time & $210.76_{1,28}$ & $<0.001^{\mathrm{a}}$ \\
\hline Scirtid $\times$ time & $4.74_{1,28}$ & 0.038 \\
\hline Mosquito $\times$ time & $25.65_{1,28}$ & $<0.001^{\mathrm{a}}$ \\
\hline Scirtid $\times$ mosquito & $11.23_{1,28}$ & $0.002^{\mathrm{a}}$ \\
\hline \multicolumn{3}{|c|}{ Water column productivity (nmol leucine/ml/h) } \\
\hline Scirtid & $0.73_{1,28}$ & 0.401 \\
\hline Mosquito & $5.40_{1,28}$ & $0.028^{\mathrm{a}}$ \\
\hline Time & $13.82_{1,28}$ & $<0.001^{\mathrm{a}}$ \\
\hline Scirtid $\times$ time & $0.47_{1,28}$ & 0.500 \\
\hline Mosquito $\times$ time & $2.27_{1,28}$ & 0.143 \\
\hline Scirtid $\times$ mosquito & $0.91_{1,28}$ & 0.348 \\
\hline \multicolumn{3}{|c|}{ Leaf surface productivity (nmol leucine/disk/h) } \\
\hline Scirtid & $7.64_{1,28}$ & $0.010^{\mathrm{a}}$ \\
\hline Mosquito & $11.73_{1,28}$ & $<0.001^{\mathrm{a}}$ \\
\hline Time & $2.95_{1,28}$ & 0.097 \\
\hline Scirtid $\times$ time & $3.02_{1,28}$ & 0.093 \\
\hline Mosquito $\times$ time & $0.99_{1,28}$ & 0.327 \\
\hline Scirtid $\times$ mosquito & $13.02_{1,28}$ & $<0.001^{\mathrm{a}}$ \\
\hline
\end{tabular}

${ }^{a} p$ Values that are significant following Bonferroni adjustment surfaces, and altered the community structure of microorganisms in water and on leaves. Shifts in T-RF profiles representing bacterial and fungal communities on these substrates were evident in the presence of mosquitoes and scirtids. Interactive effects between mosquitoes and scirtids were most pronounced in the leaf bacterial community, suggesting this component is important in facilitation, however, increased leaf carbohydrolytic activity and decay rates also implicate fungal activity in the interaction. Taken together, these results indicate accelerated leaf decay and microbial activity associated with beetle feeding activity may underlie scirtid-mediated facilitation of mosquito growth. The facilitative effect of scirtids is such that larger females are produced under low-resource conditions in the presence of scirtids [30]. In our study, we subjected these macroinvertebrates to similar low resource conditions and found that mosquito survival and total biomass were highest in the presence of scirtid beetles. Although not statistically significant, the trends evident in our results reflect the findings of previous studies [30] describing the facilitation of mosquitoes by scirtid beetles.

Enhancement of microbially associated decomposition enzymes, which convert particulate matter into soluble compounds, occurred in the presence of scirtids. Although scirtid-induced reductions in leaf mass have been documented previously [31], the current study is the first to indicate a microbial mechanism for leaf processing other than physical conversion of CPOM to FPOM. While the latter contributes to the pool of resources utilized by A. triseriatus, transitions between filtering (consuming FPOM and microorganisms) and browsing (consuming microbial biofilms) feeding modes are known to occur [27]. If browsing behavior is indeed more commonly exhibited by late-instar $A$. triseriatus as previously indicated, then we would expect that late-instar mosquito larvae would benefit from an increase in leaf-associated microbial biomass and fungal activity conferred by scirtid beetles

Table 4 Multivariate analysis of variance (MANOVA) for the effect scirtid beetles, mosquito larvae, and sampling time on fungal biomass and leaf associated enzyme measurements, and the standardized canonical coefficients (SCC) of the first canonical variate

\begin{tabular}{|c|c|c|c|c|c|c|}
\hline \multirow[b]{2}{*}{ Model parameters } & \multicolumn{3}{|l|}{ MANOVA } & \multicolumn{3}{|l|}{ SCC } \\
\hline & Pillai's trace & $F_{\mathrm{df}}$ & $P$ & Ergosterol & Xylosidase & Cellobioshydrase \\
\hline Scirtid & 0.227 & $3.320_{3,34}$ & $0.031^{*}$ & 0.241 & 0.559 & 0.555 \\
\hline Mosquito & 0.057 & $0.680_{3,34}$ & 0.571 & 0.911 & 0.592 & -0.858 \\
\hline Time & 0.277 & $4.340_{3,34}$ & $0.011^{*}$ & 1.09 & 0.092 & 0.179 \\
\hline Scirtid $\times$ mosquito & 0.104 & $1.320_{3,34}$ & 0.285 & 0.567 & -0.718 & 1.322 \\
\hline Scirtid $\times$ time & 0.104 & $1.320_{3,34}$ & 0.284 & 0.547 & 0.552 & -0.021 \\
\hline Mosquito $\times$ time & 0.054 & $0.650_{3,34}$ & 0.59 & -0.654 & 0.655 & 0.475 \\
\hline Scirtid $\times$ mosquito $\times$ time & 0.008 & $0.100_{3,34}$ & 0.961 & 0.523 & 0.634 & 0.523 \\
\hline
\end{tabular}

${ }^{*} P<0.05$, significance for MANOVA 
Figure 3 Fungal enzyme activity on leaf surfaces. Values are means \pm SE $(N=24)$. Lowercase letters comparisons between scirtid densities; means with the same letter not significantly different (Tukey's HSD, $\alpha=0.05$ )



through direct ingestion of microbial cells exposed or created by beetle feeding, and perhaps through direct utilization of fungal enzymes- and leaf-degradation products. Additional research is needed to determine how leaf processing is partitioned between FPOM production through invertebrate feeding and microbial metabolic activity and the relative contribution each make to the production of $A$. triseriatus.

The presence of either macroinvertebrate depressed leafassociated bacteria and their growth rates, however, the effect was most pronounced with mosquitoes alone. Productivity was higher when mosquitoes co-occurred with scirtids, suggesting that scirtids feeding may have interfered with mosquito browsing on leaf surfaces. Thus, it appears that reductions in bacterial biomass and productivity via scirtid grazing on leaf surfaces may play a role in the facilitation of mosquito growth by promoting fungal production. That mosquitoes drive down bacterial productivity on leaves is well-described by Kaufman et al. [16, 17, 19, 20]; however, this is the first study to indicate that another tree hole invertebrate may also affect bacterial productivity. Although a similar reduction in bacterial productivity in the presence of macroinvertebrates also occurred in the water column, there was no significant mosquito-scirtid interaction and thus a mosquito-grazing effect was not modified by the presence of scirtids as might be expected with increasing FPOM release. A corresponding change in bacterial abundance did not occur in response to the presence of either mosquitoes or scirtids and this is unsurprising in light of previous findings from tree holes. Kaufman et al. [17] suggested that such decoupling of bacterial abundance and growth rate may result from shifts in the structure of bacterial communities in response to macroinvertebrate presence. In this study, scirtids did affect water column bacterial community structure, as evidenced by T-RFLP results obtained from MspI digestions (Fig. 5), and is supportive of the idea that beetle presence alters bacterial groups. This effect is likely indirect, as scirtids do not graze in the water column and there is no indication that bacterial abundance or productivity in the water column increased when scirtids were present. Mos- 
Figure 4 Fungal biomass associated on leaf surfaces determined by ergosterol measurement. Values are means \pm SE $(N=24)$. Means for microcosms measured on day 40 were significantly greater than means measured on day 20 (Tukey's HSD, $\alpha=0.05$ ). No significant differences were observed among treatment within each sample date

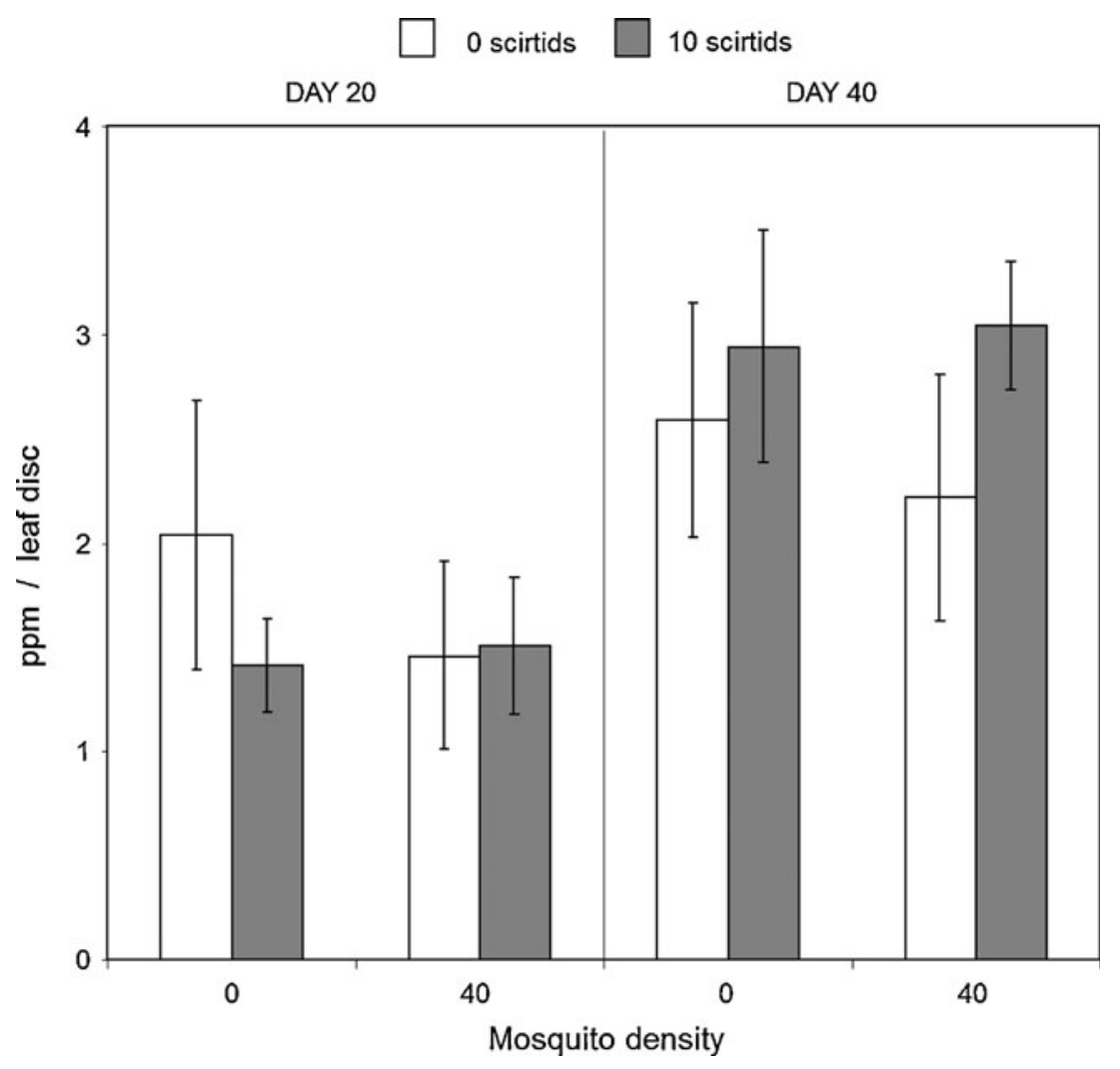

quito larvae generally had stronger influences on water column bacterial structure than scirtids, evidenced by T-RFLP results from both MspI and HhaI digestions, presumably because they directly feed upon that microbial resource. Bacterial community shifts in response to mosquito larvae have been described for pitcher plant and tree hole communities $[8,16,23]$; however, this is the first study to evaluate this response in the presence a facilitating organism.

On leaf surfaces, scirtids affected abundance and productivity of bacteria, while also altering the structure of bacterial communities. While mosquitoes altered MspI T-RF profiles of leaf bacterial communities, scirtid beetle presence was the only factor in this study associated with changes in T-RF profiles of leaf bacterial communities obtained from both MspI and HhaI digestions. Ostensibly, the more robust nature of scirtid feeding results in more dramatic changes in this microbial community than the "delicate" browsing by mosquito larvae. Similar to the changes in water column communities in response to mosquitoes, these changes likely reflect direct feeding by the beetles. In addition to the direct effect of scirtid feeding, shifts in T-RF profiles may be a response to differential enrichment of microbial communities due to increased leaf processing and macroinvertebrate waste, additions of macoinvertebrate-assoicated inocula, or the release of endophytic microorganisms or antimicrobial compounds during leaf processing. Although each of these indirect processes has the potential to alter microbial interactions, the effect of direct predation on microbial community structure has been demonstrated frequently in other systems, including mosquito habitats. In pitcher plants, another type of water-filled habitat, Peterson et al. [35] found that presence of a keystone predator, Wyomyia smithii, increased the diversity of bacterial assemblage present. It is apparent that mosquito larvae and scirtid beetles ingest microorganisms; thus, we expect that the feeding effects of these macroinvertebrates should be similar to the effects observed in other systems.

In contrast to bacterial communities, leaf surface fungal communities derived from MspI (Fig. 6) and HhaI T-RFs changed in response to mosquito larvae, but not the presence of scirtid beetle larvae. This is congruent with the findings of Kaufman et al. [16], who showed shifts in fungal community structure related to the presence or absence of $A$. triseriatus larvae in tree holes. Although leaf fungal communities were more active in their presence, scirtid beetles did not change the nature of these communities. Leaf fungal biomass in the presence of scirtids was statistically equivalent on a surface area basis (per leaf disk) compared with microcosms without scirtids, but this did not take into account the reduced leaf mass when beetles were present. Fungal biomass was presumably more concentrated on a per mass basis (same fungal mass, lower weight of each leaf disk) in the scirtid-present treatment and enzyme activity levels would have been similarly higher. We suggest that 
$16.3 \%$

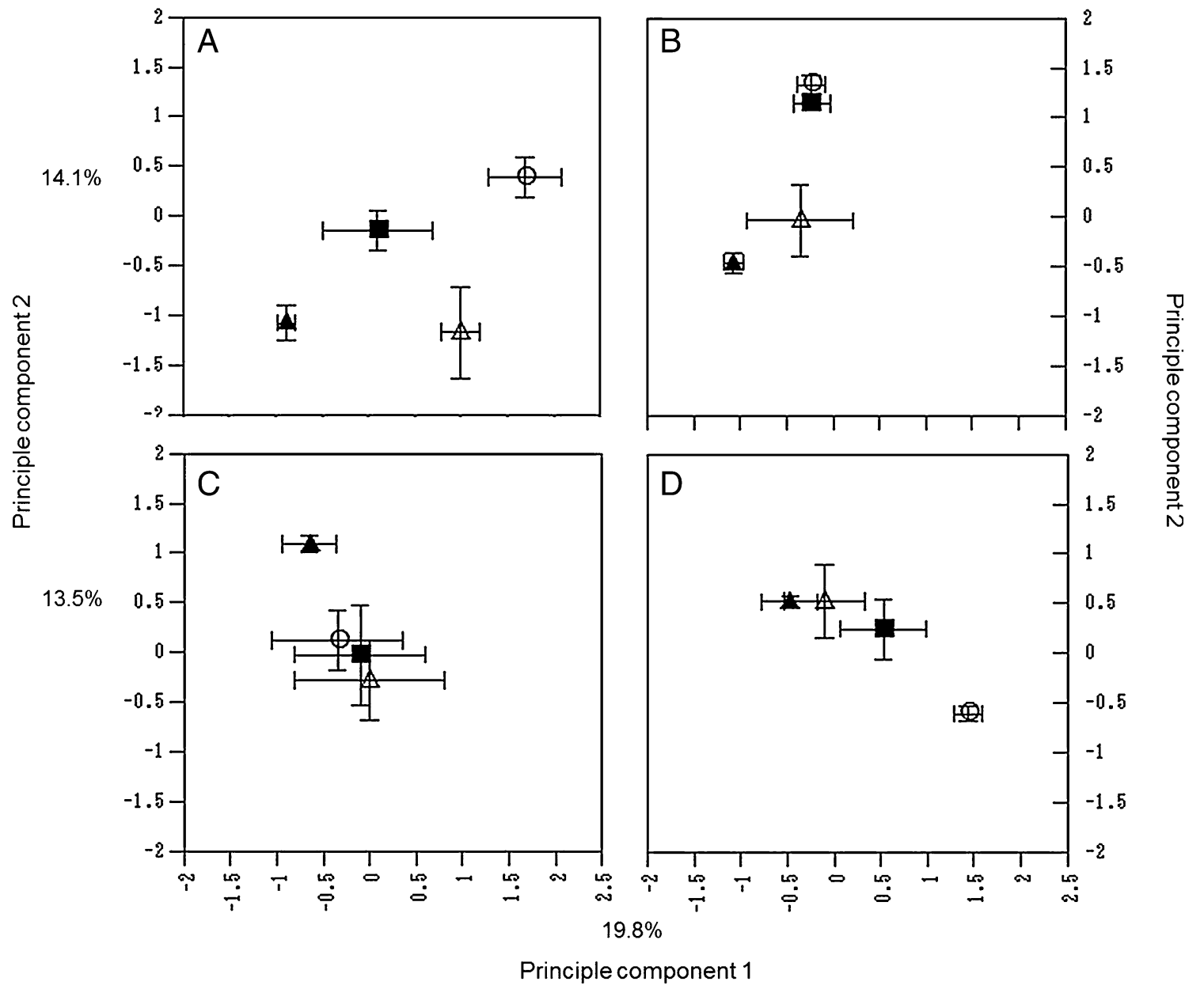

Figure 5 PCA ordination of T-RFLP peak areas representing bacterial taxa from water (a and $\mathbf{b})$ and leaf (c and $\mathbf{d})$ samples taken from microcosms on day $20(\mathbf{a}, \mathbf{c})$ and day $40(\mathbf{b}, \mathbf{d})$. Treatments are represented by the following symbols: circles 0 macroinvertebrates;

scirtid influenced concentration of existing fungal community biomass/activity may facilitatet $A$. triseriatus growth, but examination of fungal growth rates and more detailed analysis of fungal community structure (see below) is warranted in future studies.

Although leaf-associated fungal and water column bacterial communities in scirtid-only microcosms followed a similar trajectory to those with no macroinvertebrates, the influence of scirtid feeding on leaf bacterial dynamics is reflected in the differential shift of PC scores from microcosms with scirtids. That bacterial community changes evident on the leaf surface were influenced by scirtid as well as mosquito presence is unsurprising because scirtid feeding would necessarily result in the consumption of surface-associated bacterial biofilms along with leaf particulates. However, it is evident from the different principle component trajectories (Figs. 5 and 6) that these species have dissimilar squares 10 scirtids, 0 mosquitoes; open triangles 0 scirtids, 40 mosquitoes; filled triangles: 10 scirtids, 40 mosquitoes. The percentage of variance explained by PC scores for each substrate (water or leaf) is indicated on the axes for each panel

effects on the microbiota. The effect of scirtids on bacteria in the water column suggests their movements (feeding and locomotion) along leaves may dislodge surface bacteria and FPOM into the water, thus altering the bacterial community in both locations. In addition, skeletonization of leaves should increase the surface area available for bacterial biofilm formation, further contribution to changes on the bacterial communities and the observed increase in bacterial productivity in microcosms containing scirtids and mosquitoes compared to those with only mosquitoes. Overall, mosquito presence had the most influence on changes in microbial community composition. Leaf surface- and water column-associated bacterial and fungal communities all changed significantly in response to mosquito presence in correspondence with our previous observations [16, 18, 47]. Although we did not assess water column fungal biomass in the present study, we suspect that mosquitoes change fungal compo- 
$21.5 \%$

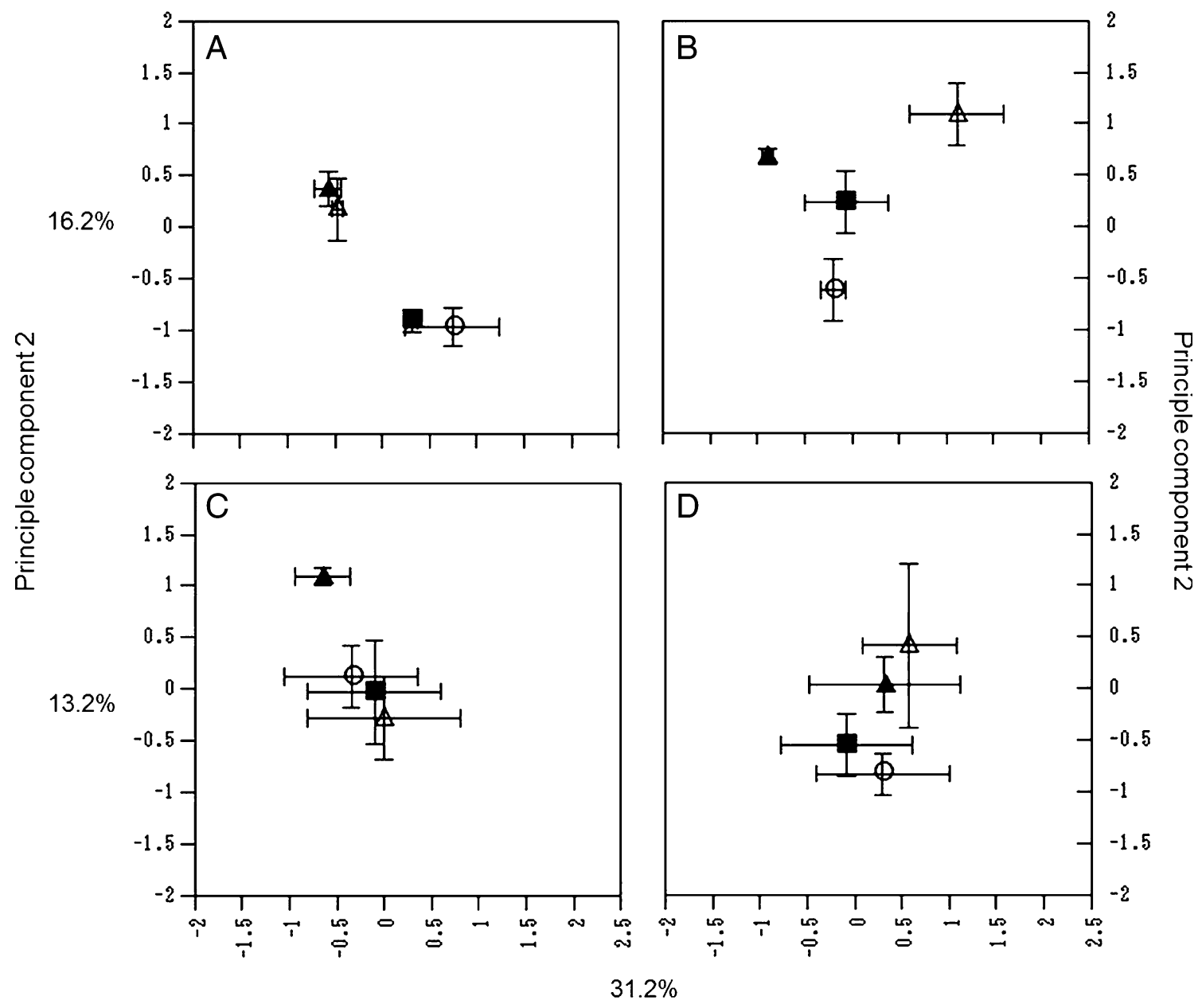

Principle component 2

Figure 6 PCA ordination of T-RFLP peak areas representing fungal taxa from water (a and b) and leaf (c and d) samples taken from microcosms on day $20(\mathbf{a}, \mathbf{c})$ and day $40(\mathbf{b}, \mathbf{d})$. Treatments are represented by the following symbols: circles 0 macroinvertebrates;

sition in the water column by reducing the taxa susceptible to larval digestion $[14,40]$.

Surprisingly, though scirtids may open additional niches for fungal colonization via shredding leaf material, scirtids did not appear to directly affect the structure of fungal communities through their feeding activity. The absence of scirtid-associated changes in the structure of leaf fungal communities may indicate these macroinvertebrates are not affecting the structure at all, or at least not at the level of resolution provided by T-RFLPs. Alternatively, changes may not be visible as a result of the technique used to harvest surface associated microorganisms from the leaf surfaces. Loosely attached fungi are represented in the sonicated leaf samples while fungi whose hyphae are squares 10 scirtids, 0 mosquitoes; open triangles 0 scirtids, 40 mosquitoes; filled triangles 10 scirtids, 40 mosquitoes. The percentage of variance explained by PC scores for each substrate (water or leaf) is indicated on the axes for each panel

enmeshed in the matrix of the decomposing leaf are not. Rather than accessing only loosely attached fungi, beetles consume whole leaf particles with the associated fungi; therefore, changes in the composition of fungal communities may be relatively uniform in contrast to the compositional changes in response to mosquitoes observed in this study and others [18]. Thus, scirtids may very well be altering leaf-associated fungal communities and increasing fungal-derived nutrients in the system via feeding on embedded fungal hyphae not measured here, however, that question should be addressed in future experiments.

The influence of time on microbial community dynamics is apparent in the high SCC values for this variable in Tables 2 and 3. Over the course of the experiment, bacterial 
abundance and productivity declined in the water column of microcosms lacking macroinvertebrates, as did the production of bacteria on leaf surfaces. In contrast, the abundance of bacteria on leaf surfaces increased with time in the nomacroinvertebrate microcosms (Fig. 2). Temporal succession is also evident in the structure of microbial communities in these microcosms (Figs. 5 and 6). Over time, PC scores from T-RF profiles shifted even in the absence of macroinvertebrates. However, the trajectories of PC scores representing microbial communities without macroinvertebrates generally differed in magnitude and direction from the trajectories of communities exposed to macroinvertebrate feeding, suggesting that these consumers play a more complex role in microbial dynamics than simply increasing the speed of microbial succession.

As shredders, scirtid feeding in tree holes accelerates detrital processing by reducing leaf material into finer fragments and variation in the condition of available resources is postulated to underlie the stochastic distribution of scirtid beetles occupying nearby tree hole such that tree holes with high quality litter resources are likely to harbor scirtid populations [29-31]. From a mosquito's perspective, scirtid feeding alters detrital surfaces and water column content, thus directly impacting the primary larval feeding zones. Leaf surfaces in particular are a tough, non-nutritive vehicle upon which resides a film of rich nutrients incorporated as microbial biomass. Although bacteria in this biofilm are severely grazed down by mosquito larvae, fungal members of this biofilm are less susceptible because they are anchored into the matrix of decaying tissue itself. Scirtid feeding may make this resource more available to larvae by exposing hyphae and/or releasing small, ingestible fragments containing fungal hyphae into the filter feeding zone. That scirtid feeding altered water column fungi supports the latter mechanism but measurements of fungal biomass in the water column are necessary to further support this hypothesis. Because resource availability is the most important contributing factor to mosquito growth, scirtidassociated changes in the underlying structure of microbial communities and the spatial rearrangement of these communities may provide mechanisms by which scirtid beetle presence in tree holes alters mosquito success under nutrient-limited conditions.

Acknowledgments We greatly appreciate the help of Lane Frasier, Renee Bloome, and Bob Burns in scirtid collections, microcosm studies, and sample analysis. This manuscript was significantly improved by the helpful comments of four anonymous reviewers. This project was supported by National Institutes of Health award AI21884.

Open Access This article is distributed under the terms of the Creative Commons Attribution Noncommercial License which permits any noncommercial use, distribution, and reproduction in any medium, provided the original author(s) and source are credited.

\section{References}

1. Abdo Z, Schüette UME, Bent SJ, Williams CJ, Forney LJ, Joyce P (2006) Statistical methods for characterizing diversity of microbial communities by analysis of terminal restriction fragment length polymorphisms of 16S rRNA genes. Environ Microbiol 8:929-938

2. Barrera R (1996) Species concurrence and the structure of a community of aquatic insects in tree holes. J Vector Ecol 21: 66-80

3. Bradshaw WE, Holzapfel CM (1992) Resource limitation, habitat segregation, and species interactions of British tree-hole mosquitoes in nature. Oecologia 90:227-237

4. Borneman J, Hartin R (2000) PCR primers that amplify fungal rRNA genes from environmental samples. Appl Environ Microbiol 66:4356-4360

5. Carpenter SR (1982) Stemflow chemistry effects on population dynamics of detritivorous mosquitos in tree-hole ecosystems. Oecologia 53:1-6

6. Carpenter SR, Kitchell JF (1987) The temporal scale of variance in lake productivity. Am Nat 129:417-433

7. Carpenter SR, Kitchell JF (1988) Consumer control of lake productivity. Bioscience 38:764-769

8. Cochran-Stafira DL, von Ende CN (1998) Integrating bacteria into food webs: studies with Sarracenia purpurea inquilines. Ecology 79:880-898

9. Daugherty MP, Alto BW, Juliano SA (2000) Invertebrate carcasses as a resource for competing Aedes albopictus and Aedes aegypti (Diptera: Culicidae). J Med Entomol 37:364-372

10. Daugherty MP, Juliano SA (2001) Factors affecting the abundance of scirtid beetles in container habitats. J N Am Benthol Soc 20:109-117

11. Daugherty MP, Juliano SA (2002) Testing for context-dependence in a processing chain interaction among detritus-feeding aquatic insects. Ecol Entomol 27:541-553

12. Daugherty MP, Juliano SA (2003) Leaf scraping beetle feces are a food resource for tree hole mosquito larvae. Am Midl Nat 150:180-184

13. Dixon KR, Chapman JA (1980) Harmonic mean measure of animal activity areas. Ecology 61:1040-1044

14. Graça MA (2001) The role of invertebrates on leaf litter decomposition in streams - a review. Int Rev Hydrobiol 86:383-393

15. Heard SB (1994) Pitcher-plant midges and mosquitoes: a processing chain commensalism. Ecology 75:1647-1660

16. Kaufman MG, Chen S, Walker ED (2008) Leaf-associated bacterial and fungal taxa shifts in response to larvae of the tree hole mosquito, Ochlerotatus triseriatus. Microb Ecol 55:673-684

17. Kaufman MG, Walker ED (2006) Indirect effects of soluble nitrogen on growth of Ochlerotatus triseriatus larvae in container habitats. J Med Entomol 43:677-68

18. Kaufman MG, Walker ED, Smith TW, Merritt RW, Klug MJ (1999) Effects of larval mosquitoes (Aedes triseriatus) and stemflow on microbial community dynamics in container habitats. Appl Environ Microbiol 65:2661-2673

19. Kaufman MG, Bland SN, Worthen ME, Walker ED, Klug MJ (2001) Bacterial and fungal biomass responses to feeding by larval Aedes triseriatus (Diptera: Culicidae). J Med Entomol 38:711-719

20. Kaufman MG, Goodfried W, Kohler-Garrigan A, Walker ED, Klug MJ (2002) Soluble nutrient effects on microbial communities and mosquito production in Ochlerotatus triseriatus habitats. Aquat Microb Ecol 29:73-88

21. Kirchman DL (2002) The ecology of Cytophaga-Flavobacteria in aquatic environments FEMS. Microb Ecol 39:91-100 
22. Kitching RL (2001) Food webs in phytotelmata: "bottom-up" and "top-down" explanations for community structure. Ann Rev Entomol 46:729-760

23. Kneitel JM, Miller TE (2002) Resources and top-predator regulation in the pitcher plant Sarracenia purpurea inquinline community. Ecology 83:680-688

24. Liu WT, Marsh TL, Cheng H, Forney LJ (1997) Characterization of microbial diversity by determining terminal restriction fragment length polymorphisms of genes encoding 16S rRNA. Appl Environ Microbiol 63:4516-4522

25. Marchesi JR, Sato T, Weightman AJ, Martin TA, Fry JC, Hiom SJ, Wade WG (1998) Design and evaluation of useful bacteriumspecific PCR primers that amplify genes coding for bacterial $16 \mathrm{~S}$ rDNA. Appl Environ Microbiol 64:795-799

26. Marsh TL (1999) Terminal restriction fragment length polymorphism (T-RFLP): an emerging method for characterizing diversity among homologous populations of amplification products. Curr Opin Microbiol 2:323-23

27. Merritt RW, Dadd RH, Walker ED (1992) Feeding behavior, natural food, and nutritional relationships of larval mosquitoes. Annu Rev Entomol 37:349-376

28. Mills DK, Fitzgerald K, Litchfield CD, Gillevet PM (2003) A comparison of DNA profiling techniques for monitoring nutrient impact on microbial community composition during bioremediation of petroleum contaminated soils. J Microbiol Methods 54: $57-74$

29. Paradise CJ (1998) Colonization and development of insects in simulated treehole habitats with distinct resource and $\mathrm{pH}$ regimes. Ecoscience 5:39-45

30. Paradise CJ (1999) Interactive effects of resources and a processing chain interaction in treehole habitats. Oikos 85:529535

31. Paradise CJ (2000) Effects of $\mathrm{pH}$ and resources on a processing chain interaction in simulated treeholes. J Anim Ecol 69:651658

32. Paradise CJ (2004) Relationship of water and leaf litter variability to insects inhabiting tree holes. J N Am Benthol Soc 23:793-805

33. Paradise CJ, Dunson WA (1997) Insect species interactions and resource effects in treeholes: are helodid beetles bottom-up facilitators of midge populations? Oecologia 109:303-312

34. Pelz-Stelinski KS, Walker ED, Kaufman MG (2010) Senescent leaf exudate increases mosquito survival and microbial activity. Ecol Entomol 35:329-340

35. Peterson C, Day S, Wolfe B, Ellison A, Kolter R, Pringle A (2008) A keystone predator controls bacterial diversity in the pitcher-plant (Sarracenia purpurea) microecosystem. Environ Microb 10:2257-2266
36. Ponnusamy L, Xu N, Stav G, Wesson D, Shal C, Apperson C (2008) Diversity of bacterial communities in container habitats of mosquitoes. Microb Ecol 56:593-603

37. Ponnusamy L, Wesson D, Arellano C, Shal C, Apperson C (2010) Species composition of bacterial communities influences attraction of mosquitoes to experimental plant infusions. Microb Ecol 59:158-173

38. Porter KG, Feig YS (1980) The use of DAPI for identifying and counting aquatic microflora. Limnol Oceanogr 25:943-948

39. Rice WR (1989) Analyzing tables of statistical tests. Evol 43:223225

40. Rossi L (1985) Interaction of invertebrates and microfungi in freshwater ecosystems. Oikos 44:175-184

41. Scheiner SM (2001) MANOVA: multiple response variables and multispecies interactions. In: Scheiner SM, Gurevitch J (eds) Design and analysis of ecological experiments, 2nd edn. Oxford University Press, Oxford, pp 99-115

42. Smith DC, Azam F (1992) A simple, economical method for measuring bacterial protein synthesis rates in seawater using ${ }^{3} \mathrm{H}$ leucine. Mar Microb Food Webs 6:107-114

43. Suberkropp K, Weyers H (1996) Application of fungal and bacterial production methodologies to decomposing leaves in streams. Appl Environ Microbiol 62:1610-1615

44. Tryzcinski MK, Walde SJ, Taylor PD (2005) Stability of pitcherplant microfaunal populations depends on food web structure. Oikos 110:146-154

45. Walker ED, Kaufman MG, Ayres MP, Riedel MH, Merritt RW (1997) Effects of variation in quality of leaf detritus on growth of the eastern tree hole mosquito, Aedes triseriatus (Diptera: Culicidae). Can J Zool 75:706-718

46. Walker ED, Lawson DL, Merritt RW, Morgan WT, Klug M (1991) Nutrient dynamics, bacterial-populations, and mosquito productivity in tree hole ecosystems and microcosms. Ecology 72:1529-1546

47. Walker ED, Merritt RW (1988) The significance of leaf detritus to mosquito (Diptera: Culicidae) productivity from treeholes. Environ Entomol 17:199-206

48. Walker ED, Olds EJ, Merritt RW (1988) Gut content analysis of mosquito larvae (Diptera: Culicidae) using DAPI stain and epifluorescence microscopy. J Med Entomol 25:551-554

49. Xu Y, Chen S, Kaufman MG, Maknojia S, Bagdasarian M, Walker ED (2008) Bacterial community structure in tree hole habitats of Ochlerotatus triseriatus: influences of larval feeding. J Am Mosq Control Assoc 24:219-227

50. Yee DA, Juliano SA (2006) Consequences of detritus type in an aquatic microsystem: effects on water quality, micro-organisms and performance of the dominant consumer. Freshw Biol 51:448 459 